\title{
Perception analysis of students and faculty of a recently implemented Interactive Teaching session in Anatomy using 'Jigsaw Technique' in a north Indian medical college
}

\author{
Shaifaly M Rustagi ${ }^{1}$, Niket Verma ${ }^{2 *}$, Suraj Prakash ${ }^{3}$, Vandana Dave $^{4}$, Ruchi Dhuria ${ }^{5}$ \\ ${ }^{1}$ Associate Professor, ${ }^{2,3}$ Assistant Professor, ${ }^{4,5}$ Tutor, ${ }^{1}$ Dept. of Anatomy and Coordinator, Medical Education Unit, ${ }^{2}$ Dept. of General \\ Medicine and Member, Medical Education Unit, ${ }^{3-5}$ Dept. of Anatomy, Army College of Medical Sciences, Delhi Cantt, Delhi, India
}

*Corresponding Author: Niket Verma

Email: drniketverma@gmail.com

\begin{abstract}
Introduction: In the new Competency Based Medical Education curriculum, interactive teaching learning has received a major thrust and it is mandated that two-thirds of the teaching schedules must comprise of interactive teaching sessions. Introduced by Elliot Aronson in 1971, the initial purpose of a Jigsaw classroom was to integrate students from different racial backgrounds. Just like every piece of a jigsaw is important to complete the picture, each student plays an important role in the jigsaw teaching session-

Aim: To assess the perception of students and faculty towards a recently conducted Interactive teaching learning session using Jigsaw technique for $1^{\text {st }}$ phase MBBS students in the department of Anatomy.

Materials and Methods: All hundred students of $1^{\text {st }}$ phase students of MBBS consented to be a part of the study. A total of 6 facilitators were part of the session. 2 rooms were used with each room having 50 students and seats pre-arranged in 10 groups with 5 seats in each group. Colour coding was followed to facilitate smooth conduct of the session. Students moved from their home groups to expert groups and back to home groups. After this the facilitators randomly selected 1 student from each of the 5 colours and asked them to present their sub-topic in front of the entire group of 50 students. At the end of the discussion, the students were administered an online quiz and an online feedback form. The principal author also conducted individual interviews with the other 5 facilitators to gather feedback.

Results: An overwhelming majority of the respondents rated the session very highly. Most of the respondents agreed that apart from gaining knowledge about the topic, attending the Jigsaw session also generated their interest in the topic and motivated them to read further about the topic. Respondents also found the quiz very useful.

Conclusion: Cooperative peer assisted learning empowers students and has the potential to reduce student dissatisfaction thereby making the students more independent and self-directed learners from an early stage. These benefits make the Jigsaw technique particularly useful in the setting of limited faculty numbers and limited resources because it requires lesser number of facilitators as compared to many other interactive teaching learning techniques. The authors therefore recommend a wider implementation of interactive teaching methods especially cooperative peer-assisted learning methods across the country and in all the subjects of MBBS.
\end{abstract}

Keywords: Education, Medical, Undergraduate; Curriculum; Students; Peer group.

\section{Introduction}

The teaching of anatomy has followed a traditional pattern in most medical colleges across the world, didactic teacheroriented lectures followed by small group tutorials, histology laboratory classes and dissection on cadavers. ${ }^{1}$ Despite all the criticism, didactic lectures have many inherent advantages including the ability to share knowledge with a large group of students in a short period of time with minimal faculty requirements as well as the ability to convey the enthusiasm of the teacher to the students thereby motivating them. ${ }^{2,3}$ With the increase in intake of MBBS students in many medical colleges over the past few years, the batch strength in the bigger medical colleges is reaching 250 or even more. However, faculty numbers have not kept up with the increase in student numbers and with many new medical colleges opening across the country, the limited faculty numbers have been stretched even further. This makes didactic lectures a preferred teaching learning technique for many departments including Anatomy.

The new Competency Based Medical Education (CBME) curriculum for undergraduate medical education has been introduced in India from August 2019 onwards. In the CBME curriculum, interactive teaching learning has received a major thrust and it is mandated that two-thirds of the teaching schedules must comprise of interactive teaching sessions while didactic lectures must be limited to not more than one-third of the schedules. ${ }^{4}$

Jigsaw teaching is a cooperative learning technique and is one of the many types of interactive teaching-learning techniques. Introduced by Elliot Aronson in 1971 in Texas, USA, the initial purpose of a Jigsaw classroom was to integrate students from different racial backgrounds in the recently desegregated schools of Austin. Just like every piece of a jigsaw is important to complete the picture, each student plays an important role in the jigsaw teaching session. ${ }^{5}$ The participants (learners) start from home groups, move to expert groups and again return to their home groups, learning from one another and sharing knowledge along the way. Knowledge is divided into smaller pictures which are learnt by students individually and the knowledge of all students combines to form the big picture in the last step of the Jigsaw. Johnson and Johnson have defined cooperative learning as a "set of methods in which students work together in small groups and help one another to achieve learning objectives". ${ }^{6}$ and cooperation is the key to the success of the Jigsaw technique. One of the purposes of conducting a Jigsaw classroom is to inculcate the spirit of cooperative peer-assisted learning in the students because once the five elements of cooperative learning are present in the classroom setting, the students tend to achieve better 
learning skills and the role of the teacher changes from being the 'sage on the stage' to becoming the 'guide on the side'?

Jigsaw teaching is being increasingly discussed in faculty development programmes across the country but very few faculty members have actually implemented this innovative teaching learning method in their institutions. The authors aim to conduct a pilot study on the implementation of a Jigsaw Teaching module in the department of Anatomy for $1^{\text {st }}$ phase MBBS students of the 2019 batch (the first batch learning under the new CBME curriculum) and take feedback from the students and faculty facilitators. This will be helpful to recognize the challenges that faculty in our institution and other institutions across the country may face in implementing Jigsaw Teaching and ways to overcome those challenges.

\section{Aims and Objectives}

The current study aims to assess the perception of students and faculty towards a recently conducted Interactive teaching learning session using Jigsaw technique for $1^{\text {st }}$ phase MBBS students in the department of Anatomy.

\section{Objectives}

1. Implementation of an interactive teaching learning session using Jigsaw technique in the department of Anatomy

2. Sensitization of student learners and faculty facilitators for successful implementation of the Jigsaw technique

3. Assessment of student perception towards Jigsaw technique by using feedback questionnaire

4. Assessment of faculty perceptions towards Jigsaw technique by using personal interviews

\section{Materials and Methods}

The Jigsaw teaching session was conducted in the department of Anatomy at our medical college. All $1001^{\text {st }}$ phase students of MBBS consented to be a part of the study. A total of 6 facilitators were part of the session, 5 from the department of Anatomy and 1 from the department of General Medicine. All facilitators were adequately sensitized and the module for the session was prepared in consultation with all facilitators. The topic selected for the session was 'Embryological development of the Heart'. The topic was divided into 5 sub-topics namely -

1. Introduction to development of Heart,

2. Folding of Heart Tube,

3. Development of Atria,

4. Development of Ventricles and

5. Anomalies of development of Atria and Ventricles.

Printed handouts were prepared for each sub-topic.

Two rooms were used for conducting the Jigsaw session. Each room was prepared to hold a Jigsaw session for 50 students with seats pre-arranged in 10 groups with 5 seats in each group. The seats were assigned roll numbers with 5 consecutive roll numbers assigned in each group e.g. roll numbers 1-5 in one group, roll numbers 6-10 in the next group and so on.
The session was conducted during the 2-hour histology laboratory class slot from 1130-1330 hrs. At the start of the session, students from roll numbers 1-50 and 51-100 were assigned to rooms A and B respectively. Students were asked to sit according to their roll numbers and leave the seats of the absentee students empty. Each seat had a coloured sticker and the students were asked to stick the coloured sticker on their aprons, with each group having only 1 student of a particular colour e.g. 1 red, 1 green, 1 yellow, 1 orange and 1 purple in each group. Each such group will henceforth be referred to as 'Home Group' and there were a total of 10 such home groups in each room.

After this the facilitators ( 3 in each room) sensitized the students about the Jigsaw teaching methodology and explained the different steps of the technique. The topic was introduced and the students were informed about the $5 \mathrm{sub}$ divisions of the topic. Printed handouts for each subtopic had been colour coded with the same 5 colours and the facilitators distributed them to the matching colour coded students in each group. The students were then asked to read their handouts (silently, without discussion) in their home groups for 10 minutes.

At the end of 10 minutes a bell was rung by the facilitators and the students were instructed to assemble in 5 colour coded zones ( 4 in the 4 corners and 1 at the centre of the room containing a big coloured board, each zone representing 1 colour, the colours being the same as used to colour code the students and the handouts) as per their colours e.g. all yellows to meet in the yellow zone, all purples to meet in the purple zone and so on. These were the 'Expert Groups' with each expert group consisting of 10 similarly colour coded students. As per the instructions, the students now discussed their sub-topic within their expert groups with the aim of ensuring that all of them were able to impart similar knowledge of their sub-topic to their home groups in the next stage of the session. The facilitators encouraged all the expert groups to follow group dynamics and to allow all the members to share their ideas. This stage lasted for 15 minutes.

At the end of 15 minutes, the students reassembled in their original home groups. The colour sequence of topics was displayed on the screen and boards in the room and the students followed the same sequence for discussion of their sub-topics. The students brought back what they had learnt in the expert group and shared the knowledge within their respective home groups. Each sub-topic was allotted 10 minutes, and a bell was rung at the end of every 10 minutes for time bound switching over to the next topic. The groups were encouraged to follow group dynamics and the name of the colours was also sequentially announced by the facilitators to prevent any confusion among students. At the end of 50 minutes all the students had shared their knowledge of their sub-topics within their home groups and the topic had been covered starting from the basics and leading to the clinical correlation.

After this the facilitators randomly selected one student from each of the 5 colours and asked them to present their sub-topic in front of the entire group of 50 students. 
Students were permitted to use chalk and board in this step. At this stage the students were encouraged to ask any doubts or queries which were readily answered by the facilitators.

At the end of the discussion, the students were administered an online quiz to be completed between 13201330 hours and an online feedback form to be completed by the end of the day (both using Google Forms).For the purpose of obtaining feedback, the principal author also conducted individual interviews with the other 5 facilitators.

\section{Results}

A total of 77 students responded to the feedback form. The results are presented point-wise below.

1. 67 respondents $(87 \%)$ said they were attending a Jigsaw teaching learning session for the first time.

a. 73 respondents agreed that the session started and finished as per schedule.

b. 75 respondents agreed that the session was conducted in a safe, non-threatening environment.

c. 72 respondents agreed that the session was conducted without unnecessary interruptions.

2. Feedback regarding the facilitators -

a. 76 respondents agreed that the facilitators explained the steps of Jigsaw at the beginning of the session.

b. 70 respondents agreed that the facilitators guided them through the different stages of the Jigsaw session.

c. 76 respondents agreed that the facilitators encouraged all students to participate actively in the Jigsaw session.

d. 72 respondents agreed that the facilitators helped facilitate discussion within the home groups and expert groups.

e. 67 respondents agreed that the facilitators answered any queries/doubts asked by the students.

3. All 77 respondents $(100 \%)$ agreed that attending the Jigsaw session generated their interest in the topic being covered (Fig. 1)

4. 76 respondents $(98.7 \%)$ agreed that by attending the Jigsaw session, they were able to gain more knowledge about the topic being covered (Fig. 2)

5. 76 respondents $(98.7 \%)$ agreed that after attending the Jigsaw session, they were motivated to read further about the topic (Fig. 3)

6. Feedback regarding the post-session quiz

a. 71 respondents $(92.2 \%)$ attempted the post-session quiz

b. All the 71 respondents who attempted the quiz found the quiz useful

7. 12 respondents $(15.6 \%)$ respondents still had unanswered queries regarding the topic that was covered in the Jigsaw session. (in the subsequent section of the feedback form students were asked to list their unanswered queries or doubts and were assured that all the queries will be answered in the next session.

8. In the next section of the feedback form respondents were asked that in their opinion, what was the best part of the Jigsaw session. Some of the responses are posted verbatim below -

a. "We feel comfortable in clearing our doubts"

b. "The part where all people who had read the same topic discussed it thereby promoting even better understanding of the topic"

c. "The discussion about the topic was very helpful and sparked a different kind of interest in embryology"

d. "The integration of topics in the home groups by the experts"

e. "When you were given a topic to explain to your team, you were supposed to understand the topic completely. That to me was the best part"

f. "Interacting and learning from friends. One can ask even the silliest of doubts."

g. "The part where we had to teach our parent group our respective topics. As we had discussed it amongst our expert groups and cleared our queries with the teachers it was easy and fun."

h. "The best part of this session was that every single detail was given for a particular topic by our batchmates. And every doubt was cleared."

i. "The explanation and learning of 4 topics at home group was best where I have prepared only one but $\mathrm{i}$ have gained knowledge of all 4 topics."

j. "The best part of this JIGSAW is everyone has to teach something to someone"

k. "We all participated among students that eliminated nervousness regarding asking doubts,presentation etc."

1. "I was able to cover the topic in less time"

m. "Different Colors given to each person"

n. "Explaining topic to others raise my confidence level also understand and remember that for long time."

o. "Students assigned same topics coming together to achieve a common and satisfactory explanation regarding the topic. The discussion was good and doubts were also solved."

p. "The best part was that it involved us in the session."

q. "The fact that we all taught each other like mature learners; the environment, which encouraged us to ask our doubts intergroup and intragroup."

9. In the next section the respondents were asked to rate the Jigsaw session on a 5 point Likert Scale. $26(33.8 \%)$ respondents ranked the session 5 out of $5,44(57.1 \%)$ ranked it 4 out of 5 and $7(9.1 \%)$ ranked it 3 out of 5 . (Fig. 4)

10. $71(92.2 \%)$ agreed that the Jigsaw technique was better than a traditional didactic lecture. (Fig. 5) Students were then asked to explain their answer in favour or against Jigsaw as compared to Traditional didactic lectures. Some of the responses are posted verbatim below -

a. "Jigsaw is a good method because in this we discuss with our batchmates so we can understand well and clear our queries."

b. "It was Very interactive" 
c. "It helps to analyse how much we learned as we have to teach others also."

d. "One does not and cannot afford to feel sleepy during a JIGSAW class, unlike a traditional lecture. That is very very helpful."

e. "In traditional method it's usually one way communication but in this method student participation was maximum so it had our attention the whole time and later all our queries were answered by the teachers so we were not left with any doubts."

f. "The session was better than the lecture because this created more interactive session and explanations were also made so efficiently"

g. "Group discussion is more better as we learn more with friends. But teacher is always an essential part."

h. "Its time consuming but the topics will be more clear."

i. "We actually took interest in the topic instead of focussing on copying notes. As we were discussing amongst our friends it was easier to clear doubts and ask questions. Also it helped build up confidence."

j. "Jigsaw is better than traditional lecture because students don't hesitate in asking doubts/questions from batchmates \& also students can't sleep in jigsaw session"

k. "The jigsaw method is really innovative, the only drawback was that we should have been given more time to explain our topic, otherwise it was very helpful"

1. "I think JIGSAW method is nice because it involves active participation by us and increases our curiosity too regarding that topic."

m. "I am in favour of it because in this all efforts are made by student to make the topic more understandable to the group members."

n. "Discussion helps one learn better and is retained for longer duration. It helped covering the topic in less time. The JIGSAW was very interactive from student's perspective unlike the traditional lecture."

o. "Jigsaw cannot replace the expert input by the faculty members, as the students grasping the subject have different levels of understanding, which leads to gaps in the knowledge of the topic."

p. "Jigsaw was quite time consuming as compared to traditional lecture."

q. "Some students of the home grp who have less understanding capacity not able to tell about their topic, so topic is not clearly understood."

11. When asked whether they would like to attend more Jigsaw sessions in Anatomy, 74 (96.1\%) respondents answered the question in affirmative.

12. The respondents were asked to suggest additional topics from Anatomy which should be taught through Jigsaw method. Different topics covering almost all major topics of Anatomy were suggested but among them embryology, histology and upper limb topics were suggested by the maximum number of students.
13. Finally, the respondents were asked to give any further suggestions /feedback for further improvement. Some of the responses are presented verbatim below -

a. "The session was perfect."

b. "Timing for discussion should be increased"

c. "More faculty members to be with each expert group to enable better direction of learning."

d. "Some time also given to read all the topic atleast once"

e. "The session was great, doesn't need improvements"

f. "Give the printed note of every group to each student."

g. "a teacher should be provided to every expert group so that any sort of doubt to should be cleared at the spot"

h. "It can be conducted per week since it improves our thinking skills and make us more enthusiastic towards our studies."

14. The faculty/facilitators expressed satisfaction with the Jigsaw technique. All of them felt that it was a feasible interactive teaching learning method. However, 2 facilitators felt that the Jigsaw was more time consuming than a lecture and only specific topics could be adapted to this teaching technique.

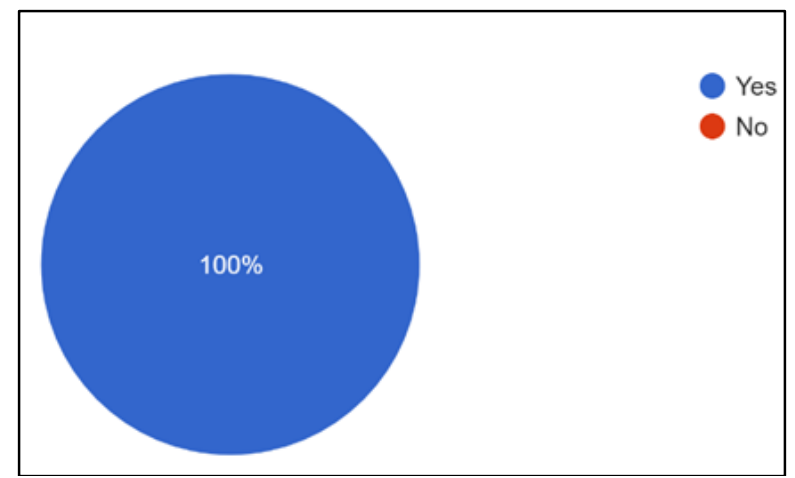

Fig. 1: Did attending the JIGSAW generate your interest in the topic being covered?

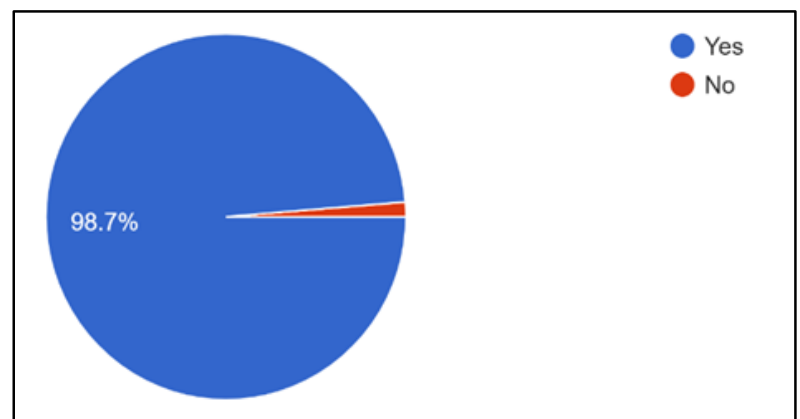

Fig. 2: By attending the JIGSAW, were you able to gain more knowledge about the topic being corved? 


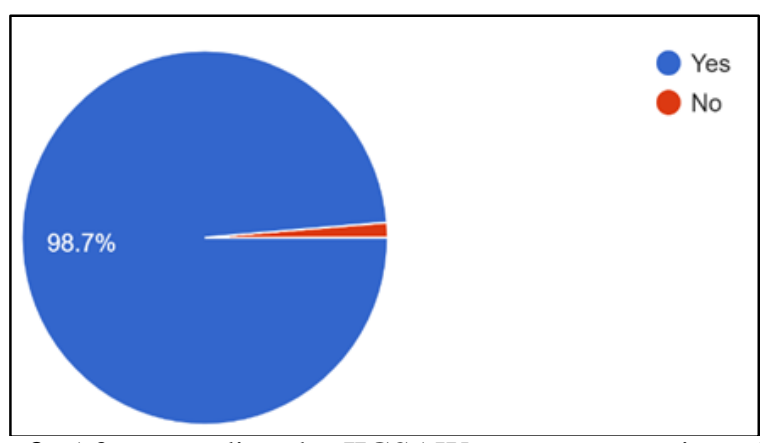

Fig. 3: After attending the JIGSAW, were you motivated to read further about the topic that was covered in the session?

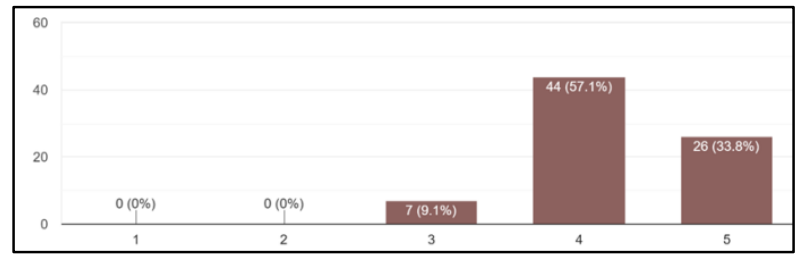

Fig. 4: Overall, on a scale of 1 to 5, how will you rate the JIDSAW session conducted on 14/11/2019?

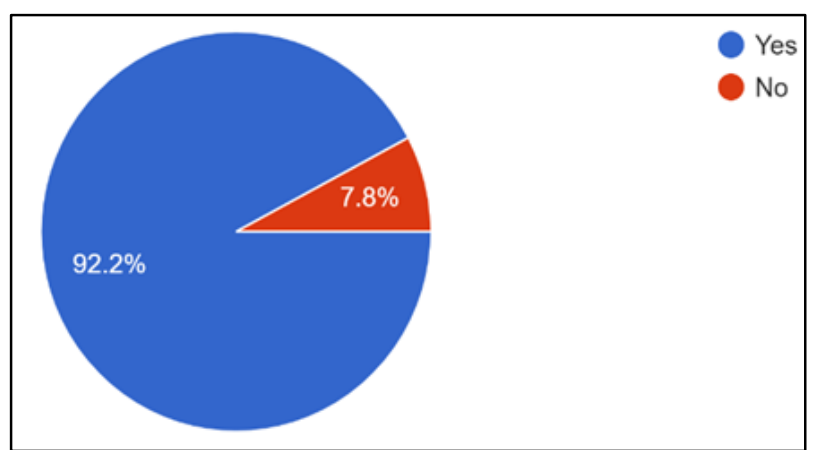

Fig. 5: In your opinion, is JIGSAW better than a traditional lecture?.

\section{Discussion}

The Jigsaw technique is cooperative peer-assisted learning at its best, wherein each student shares knowledge with and also learns from his/her peers in a small group. As we can observe from the results of this study, the Jigsaw method received approval from an overwhelming majority of the student respondents. A common point in favour was the fact that students felt more comfortable in discussing with and asking questions from their peers in a small group setting. Peer assisted learning has been shown to promote active engagement of students in the learning process. ${ }^{8}$ Previous studies have shown that peer tutoring increases the motivation to learn and improves cognitive processing of the peer tutors. ${ }^{8}$ Annis in his study compared 3 randomly allocated groups of students namely, read only, read to teach and read and teach. The study demonstrated that the read and teach group benefitted more than the read to teach which benefitted more than the read only group. ${ }^{9}$ Similar findings were reported by Benware and Deci. ${ }^{10}$

Studies have shown that peer tutors report a positive attitude towards learning and improved confidence in their ability to teach and communicate with their peers. Helping others can also give them a sense of satisfaction with the process. ${ }^{11}$ The peer tutees have also been shown to benefit from peer-assisted teaching learning. The lower 'pupil/teacher' ratio has been shown to increase both the time spent on the task by each student and the opportunities to contribute to the discussion, express their opinions and learn from others. Peer assisted teaching learning has exhibited not only cognitive gains but also better retention of knowledge, better clinical correlation and improved selfesteem, confidence and empathy. ${ }^{8}$

In their study Moust and Schmidt compared the academic achievements of students guided by staff tutors with students guided by student tutors. They found that students preferred peer tutors because they were less authoritarian and were able to understand their problems better than staff tutors. ${ }^{12}$ In the Jigsaw process the students are required not only to individually learn the given reading material but to help each other in learning the assigned material in the expert group stage. After this they move back to home groups where they not only share their knowledge but also learn to listen to others and learn from their peers. This exchange of ideas and the cooperative discussion enhances not only the cognitive but also the affective and psychomotor skills of the students. Since all the students are an important piece of the jigsaw puzzle, this feeling of having an important role in building up the complete/big picture, the feeling of satisfaction by sharing their knowledge with their peers, the feeling of being involved in the process of learning helps enhance each students' central role in the construction of new knowledge. ${ }^{13}$

Students who favoured traditional lectures over the Jigsaw method were of the opinion that the Jigsaw was more time consuming, an opinion also echoed by 2 of the faculty facilitators. Other respondents mentioned that due to different levels of understanding, some peer tutors were not able to explain their topic properly which lead to knowledge gaps in key concepts. They felt that the role of the teacher could not be replaced by peer tutoring.

Peer assisted learning, like all other forms of teaching learning, is not free of disadvantages. The findings of previous studies agree with the feedback of the respondents of our study. Training the faculty, sensitizing the students, adapting the topics into smaller sub-topics and preparing the learning materials are activities that need time especially in the initial sessions. Some peer tutors may not be able to 'teach' as well as other peer tutors or the teachers and therefore the coverage of content may be variable. Training these peer tutors may impose additional burden on the time and resources. Therefore, the authors advice that faculty members should initially implement Jigsaw technique on smaller non-critical topics to allow time for adjustment of students and faculty to the new technique. ${ }^{14}$

In response to suggestions for better implementation of this technique many students suggested that they wanted more faculty facilitators to be present during the session with few students even requesting one facilitator for every home group. This reflects the deep-rooted culture of 
dependency on teachers that is inculcated in the students from the start of school life and which continues till the end of higher education. Peer assisted learning, which is an essential component of Jigsaw technique, seeks to democratize learning by delegating the management of learning to the learners themselves. In our study an overwhelming majority of respondents agreed that apart from gaining knowledge about the topic, attending the Jigsaw session also generated their interest in the topic and motivated them to read further about the topic. This shows that cooperative peer assisted learning empowers students and reduces their dependency on replication of what the faculty teach them in class and has the potential to reduce student dissatisfaction. In the long run this will make the students more independent and self-directed learners from an early stage. These benefits make the Jigsaw technique particularly useful in the setting of limited faculty numbers and limited resources because it requires lesser number of facilitators as compared to many other interactive teaching learning techniques. ${ }^{8}$ We agree that the culture shift will take time but we have to start now to effect any meaningful change in the near future. The authors therefore recommend a wider implementation of interactive teaching methods especially cooperative peer-assisted learning methods across the country and in all the subjects of MBBS.

\section{Source of Funding}

None.

\section{Conflict of Interest}

None.

\section{References}

1. Waghmare JE, Sontakke BR, Tarnekar AM, Bokariya P, Wankhede V, Shende MR. Reciprocal peer teaching: An innovative method to learn gross anatomy. J Mahatma Gandhi Inst Med Sci. 2010;15:40-3.

2. Dipiro JT. Why do we still lecture? Am J Pharm Educ. 2009;73:137.
3. Nierenberg DW. The challenge of "teaching" large groups of learners: strategies to increase active participation and learning. Int J Psychiat Med. 1998;28(1):115-22.

4. [Internet]. Mciindia.org. 2019 [cited 2 May 2020]. Available from: https://mciindia.org/ActivitiWebClient/open/getDocument?pat $\mathrm{h}=/$ Documents/Public/Portal/Gazette/GME-06.11.2019.pdf

5. The Jigsaw Classroom [Internet]. Jigsaw.org. 2020 [cited 2 May 2020]. Available from: https://www.jigsaw.org/\#overview

6. Johnson D, Johnson R. An Educational Psychology Success Story: Social Interdependence Theory and Cooperative Learning. Educ Res. 2009;38(5):365-79.

7. Johnson D, Johnson R, Holubec E. The New Circles of Learning: Cooperation in the Classroom and School. Assoc Supervision Curriculum Dev. 1994.

8. Topping KJ. The effectiveness of peer tutoring in further and higher education: A typology and review of the literature. Higher Educ. 1996;32(3):321-45.

9. Annis LF. The processes and effects of peer tutoring. Human Learning: Journal of Practical Research \& Applications 1983;2(1):39-47.

10. Carl B \& Edward D. Quality of learning with an active versus passive motivational set. Am Educ Res J. 1984;21:755-65.

11. Dillner M. Tutoring by Students: Who benefits? Gainesville, f: Florida Educational Research and Developmental Council; 1971. n1-2.

12. Moust J, Schmidt H. Effects of staff and student tutors on student achievement. Higher Educ. 1994;28(4):471-82

13. Dat T. The Effects of Jigsaw Learning on Students' Knowledge Retention in Vietnamese Higher Education. Int $J$ Higher Educ 2016;5(2).

14. Greenwood CR, Carta JJ, Kamps D. 'Teacher-mediated versus peer-mediated instruction: a review of educational advantages and disadvantages', in Foot, H.C., Morgan, M.J. and Shute, R.H. (eds.), Children Helping Children. London and New York: John Wiley; 1990:177-205.

How to cite: Rustagi SM, Verma N, Prakash S, Dave V, Dhuria R. Perception analysis of students and faculty of a recently implemented Interactive Teaching session in Anatomy using 'Jigsaw Technique' in a north Indian medical college. J Educ Technol Health Sci. 2020;7(1):1722 